\title{
La protesta de Wittenberg (1517): Perspectivas teológicas desde el contexto latinoamericano (2017)
}

\author{
Victorio Araya-Guillén*
}

Recibido: 23 de febrero, 2016 - Aceptado: 26 de octubre, 2016

\section{RESUMEN}

Se parte de la protesta de Martín Lutero en octubre de 1517 contra las indulgencias. Se ubica su descubrimiento de la gracia en el contexto de su dramática lucha espiritual. Se destacan los fundamentos de la interpretación evangélico-protestante, expresados en la palabra sola, y tres corolarios: libertad, sacerdocio universal y el testimonio del Espíritu Santo. Se concluye con una reflexión sobre el aporte de la Reforma en Latinoamérica. Se destacan tres ejes: la iglesia semper reformanda, el principio de crítica antiidolátrica y la primacía de la gracia como la bendición vital, el don mayor de Dios. El Espíritu de vida como el impulso para una praxis profética: la opción preferencial por la vida como manera de vivir la espiritualidad.

Palabras clave: Reforma, gracia, justificación por la fe, principio protestante, vida, espiritualidad.

\section{Formato de citación según APA}

Araya-Guillén, V. (2017). La protesta de Wittenberg (1517): Perspectivas teológicas desde el contexto latinoamericano (2017). Revista Espiga, 16(33), 1-18. DOI: http://dx.doi. org/10.22458/re.v16i33.1765

\section{Formato de citación según Chicago}

Araya-Guillén, Victorio. «La protesta de Wittenberg (1517): Perspectivas teológicas desde el contexto latinoamericano (2017)». Revista Espiga, 33 (2017): 1-18. DOI: http:// dx.doi.org/10.22458/re.v16i33.1765

* Teólogo ecuménico. Pertenece a la tradición eclesial reformada. Catedrático jubilado de la Universidad Nacional (UNA) y la Universidad Bíblica Latinoamericana. Es licenciado en Filosofía (UCR) y doctor en Teología (Salamanca, España). Es autor de varios libros, artículos y ha colaborado en varias obras colectivas. Costa Rica. unavag@gmail.com 


\section{Introducción}

Estas reflexiones hacen memoria de la protesta teológica de Martín Lutero (14831546) el 31 de octubre de 1517 en Wittenberg, Alemania. Pronto se cumplirán 500 años de la colocación de Las 95 tesis contra las indulgencias ${ }^{1}$. Esta fecha marca el punto de partida de un movimiento de reforma en el cristianismo europeo.

Hacer memoria es celebrar y reflexionar críticamente sobre la pertinencia de la Reforma, ocurrida durante el siglo XVI. Nuestro contexto histórico y eclesial es América Latina, afro-indo-latina, con su rostro de pobreza y de exclusión de la mujer, de la persona indígena, afrodescendiente y migrante. Además, caracterizada por su diversidad cultural, religiosa, familiar, sexual.

Se mira al pasado, con el propósito de radicalizar la Reforma del siglo XVI y transformarla en jubileo liberador, para seguir caminando hacia el mundo justo de Dios, y así afirmar nuestra herencia e identidad protestante-reformada, sin perder la memoria histórica de los pobres.

Elsa Tamez ha señalado muy oportunamente en su estudio doctoral, sobre la Reforma y la justificación por la fe, que «un contexto donde los pobres son amenazados exige que se ponga el acento en la justicia y la gracia de Dios, las cuales elevan a la persona excluida a la dignidad de hijo e hija de Dios. [...] Cuando se acoge el don de la justificación, se defiende el derecho a la vida $»^{2}$.

\section{PARTE PRIMERA: \\ Wittenberg 1517}

Con la protesta religiosa de Martín Lutero, da inicio una gran transformación en la Iglesia y en la sociedad europea del siglo XVI. La Reforma religiosa en Europa se convirtió en un movimiento liberador ${ }^{3}$, en el marco de la crisis del sistema feudal y de la poderosa estructura de la Iglesia romana, dominante en lo cultural y religioso. Se pensaba que Dios había establecido una doble autoridad: el emperador, como gobernante de la vida terrena, y la Iglesia, encabezada por el papa, como mediadora indispensable del destino eterno de los seres humanos.

El teólogo e historiador alemán, Martín Hoffmann afirma que «las 95 Tesis de Martín Lutero no solo fueron una estocada en el corazón de la iglesia católico romana, sino igualmente en el corazón del sistema de poder feudal en su conjunto» ${ }^{4}$.

1. Se sigue la versión española del «Predicador Evangélico», recogida por Ingeborg Stolee (1955, 134-138).

Las Tesis están disponibles en la siguiente página electrónica de internet: https://es.wikisource.org/wiki/ Las_noventa_y_cinco_tesis.

Sobre la vida de Lutero, existe la histórica y clásica versión cinematográfica de 1954, Lutherans, Film Associates y la de 2004, Martin Luther, Pensilvania, Gateway Films. Recuperada en internet: https://www. youtube.com/watch?v=jyiCLyqRdoU

2. Elsa Tamez, «Justificación y justicia», en Nuevo Diccionario de Teología, dirigido por Juan José Tamayo, (Madrid: Trotta, 2005), 508-517.

3. Richard Shaull, La Reforma y la teología de la liberación (San José: DEI, 1993), 23.

4. Martin Hoffmann, La locura de la Cruz. La teología de Martín Lutero (San José: DEI, 2014), 23. 
La intención de Lutero con la divulgación de su documento Una disputa sobre el poder y eficacia de las indulgencias, fue seguir una antigua práctica académica. Esta planteaba un reto con el fin de realizar un debate teológico. De ahí la forma de presentar las tesis colocándolas públicamente en la llamada «Iglesia del Castillo» de Wittenberg. Para su sorpresa, el documento circuló con rapidez por toda Alemania. Un mes después, por toda Europa. En realidad, las tesis no eran un repique de campanas que llamaban a una reforma en la Iglesia. Ese llamado debe reservarse para los polémicos escritos de 1520: Discurso a la nobleza cristiana de la nación alemana y La cautividad babilónica de la igle$s i a^{5}$. En noviembre de ese mismo año, Lutero publicó La libertad cristiana.

Cuando Lutero escribió en 1517 Las 95 tesis fue una voz más de una serie que desde hacía más de un siglo venía protestando contra la situación reinante en la Iglesia: sus prácticas distorsionadas, su poder, su enriquecimiento, su corrupción y la falta de espiritualidad. Entre estas voces destacaron, en Inglaterra, Juan Wycliffe (1330-1384); en Bohemia, el teólogo Juan Hus (1373-1415) y el reformador laico, Jerónimo de Praga (c.1371-1416); y en Italia, el predicador Jerónimo Savonarola (1452-1498) 7 .

Lutero, a riesgo de perder su vida en la hoguera, estaba determinado a no callarse ni retractarse ante la poderosa Iglesia romana y defender la buena nueva del evangelio de la gracia.

\section{El poder y eficacia de las indulgencias}

El verdadero tesoro de la Iglesia es el Santísimo Evangelio de la gloria y la gracia de Dios (Tesis 62) ${ }^{8}$.

La venta de las indulgencias era impulsada por el papa León X, quien estaba urgido de dinero para reconstruir la Catedral de San Pedro en Roma. Se ofrecían como un medio de alcanzar el perdón de Dios; de tal manera, se hacía creer a los fieles que la salvación se podía comprar. Cuando Lutero escuchó a Tetzel (1465-1519), responsable de la venta de las indulgencias en Alemania, quedó indignado.

La publicación del documento El poder y eficacia de las indulgencias, conocido como Las noventa y cinco Tesis, fue determinado por una práctica académica medieval, que autorizaba a cualquier doctor en Teología (Lutero lo era desde 1512) para proponer una discusión pública. El punto central de la propuesta estaba claro: no se puede comprar la misericordia de Dios; Dios no vende nada; la fe es la confianza en Dios quien salva gratuitamente.

5. Martin Lutero, Páginas escogidas (Buenos Aires: La Aurora, 1961), 31-45.

6. Roland H. Bainton, Lutero, (Buenos Aires: Sudamericana, 1955), 178-182.

7. Lavinia Cohn-Sherbock, Quién es quién en el cristianismo (Madrid: Acento, 2002).

8. Ingeborg Stolee, Vida de Lutero (Minneapolis: Augsburg, 1955), 137. 
Las raíces de la protesta de Lutero se pueden retrotraer a los días en que, como joven profesor de Teología, estudiaba y enseñaba Biblia: Salmos (en 1513), Romanos (en 1515).

Lutero vivía con angustia su profundo dilema espiritual. Vivía temeroso de un Dios justiciero. ¿Cómo, entonces, alcanzar su misericordia? ¿Cómo amar a Dios y gozar de su amistad?

En 1505 Lutero había sido sorprendido por una tormenta. Escapó de morir por un rayo que lo arrojó a tierra. Clamó al cielo: «¡Santa Ana, ayúdame! ¡Me haré monje!»" Ese mismo año, ingresó en el riguroso monasterio de la Orden de los Ermitaños de San Agustín. Su anhelo era tener paz con Dios, aceptando la disciplina y autoridad de la Iglesia que se presentaba como mediadora de la salvación. Aceptó cumplir con los votos de pobreza, castidad y obediencia, y someterse a las renuncias que fueran necesarias: morir a sí mismo, al mundo y a la carne; castigar el cuerpo y renunciar a la familia y los amigos.

Sin embargo, la meta anhelada por Lutero se convirtió en todo lo contrario. El cumplimiento riguroso de sus prácticas como monje no lograron apaciguar la angustia. Se creía tan sumido en el pecado que vivía temeroso de un Dios furioso, cuyas demandas eran demasiadas para su fragilidad humana. La Iglesia no anunciaba el amor de Dios y daba más énfasis a sus juicios condenatorios.

Lutero llegó a preguntarse: ¿Es Dios en verdad justo y amoroso? Experimentaba lo contrario: «No amaba al Dios justo que castiga los pecadores, sino más bien lo odiaba y murmuraba contra Élı ${ }^{10}$.

Entender la agónica lucha interior de Lutero y cómo logró liberarse al descubrir la gracia y la justificación por la fe, es comprender el corazón ardiente de su experiencia evangélica, la centralidad de la gracia en la teología de la Reforma: la salvación es don, generosidad de Dios, y no mérito humano (como se explicará más adelante).

$\mathrm{Su}$ descubrimiento liberador no había nacido en la soledad de un convento, ni en las aulas de la universidad en polémicas con los teólogos. Se fraguó a partir de una muy intensa vivencia espiritual personal.

\section{«En tu justicia, libérame» (Sal. 31:1)}

La Biblia fue la llave que hizo posible abrir las puertas al don de Dios, su gracia, amor y su justicia misericordiosa.

En el Salmo 31, Lutero descubrió una sorprendente afirmación: «Yahvé en Ti me refugio [...] libérame en virtud de tu justicia» (31:1). Si Dios en su justicia rechaza al pecador, ¿cómo puede el salmista proclamar con certeza su confianza en la justicia liberadora de Dios? La luz comenzaba a derribar los muros de la noche que vivía su alma. Empezó a

9. Roland H. Bainton, Lutero..., 33.

10. Ibíd., 67. 
comprender, en la Biblia, la relación justicia-salvación, tan contraria al concepto de justicia judicial condenatoria. Lutero empezó a vislumbrar cómo, en la tradición profética, la justicia de Dios es salvífica y tiene que ver con misericordia ${ }^{11}$.

Jean-Pierre Prévost señala que, cuando en los Salmos se proclama la justicia de Dios, «no es la del juicio y el tribunal, sino la de la salvación y la liberación (Sal. 103:106). No se trata de una justicia que condene y aplaste, sino de una justicia que levanta y hace vivir; no de una justicia que se teme, sino de una justicia que se espera» ${ }^{12}$.

El Salmo 103:6 destaca: «El Señor hace justicia y defiende a todos los oprimidos». La historia de salvación conjuga la justicia de Dios con su misericordia o ternura: «Él ama la justicia y el derecho, y su misericordia llena la tierra» (Sal. 33:5. Cf. Sal. 72).

«El que se justifica por la fe, vivirá» (Rom.1:17)

El giro copernicano en el corazón y en la mente de Lutero se completó al estudiar la epístola a los Romanos. Descubrió y entendió el versículo 1:17, que señala lo siguiente:

[cómo] en el Evangelio se revela la justicia que Dios concede única y exclusivamente por la fe, como dice la Escritura [Hab. 2:4]: «más el justo por la fe vivirá». (Rom. 1:17).

Con ardiente anhelo ansiaba comprender la Epístola de Pablo a los Romanos y sólo me lo impedía una expresión: «la justicia de Dios», pues la interpretaba como aquella justicia por la cual Dios es justo y obra justamente al castigar al injusto. Mi situación era que, a pesar de ser un monje sin tacha, estaba ante Dios como un pecador con la conciencia inquieta y no podía creer que pudiera aplacarlo con mis méritos. Por eso no amaba yo al Dios justo que castiga a los pecadores, sino más bien lo odiaba y murmuraba de Él. Sin embargo, me así a Pablo y anhelaba con ardiente sed saber que quería decir.

Reflexioné noche y día hasta que vi la conexión entre la justica de Dios y la afirmación de que «el justo vivirá por la fe». Entonces comprendí que la justicia de Dios es aquella por la cual Dios justifica en su gracia y pura misericordia. Desde entonces me sentí como renacido y como si hubiera entrado al paraíso por puertas abiertas de par en par. Toda la Sagrada Escritura adquirió un nuevo aspecto y mientras antes «la justicia de Dios» me había llenado de odio, ahora se me tornó inefablemente dulce y digna de amor. Este texto de Pablo se convirtió para mí en una entrada al cielo... ${ }^{13}$.

El debate académico pedido no se realizó, pero la reacción de Roma no se hizo esperar: necesitaba callar a Lutero. La bula del papa León X Exurge Domine, publicada en junio de 1520, ordenaba a Lutero que se retractara, so pena de ser excomulgado como hereje. Este se negó y quemó la bula públicamente, el 10 de diciembre de 1520, desafiando el poder religioso del papa. El 3 de enero de 1521, León X firmó la bula final que confirmaba su completa excomunión.

11. Pietro Rossano, Nuevo diccionario de Teología Bíblica (Madrid: Paulinas, 1990), 985-987.

12. Jean-Pierre Prévost, Diccionario de los salmos (Estella: Verbo Divino, 1990), 31.

13. Roland H. Bainton, Lutero..., 67. 
Convocado por la Dieta imperial en Worms, en abril de 1521, en presencia del emperador Carlos V, Lutero no accedió a retractarse. Los representantes del papa se negaron a discutir. Solo querían una contestación breve a la pregunta: ¿se retracta, o no se retracta? Lutero, dándose cuenta de que «su hora gloriosa» ${ }^{14}$ había llegado, declaró:

Ya que su Majestad y sus Señorías piden una respuesta clara, les daré una que no tiene cuernos ni dientes. A menos que se me convenza con el testimonio de las Escrituras o por correcta razón - pues no creo ni en papas ni en concilios que a menudo han errado y se han contradicho entre sí- a menos de que sea convencido de esta forma, no puedo, ni quiero retractarme de nada.

Yo estoy ceñido por los textos de la Biblia, mi conciencia es cautiva de la palabra de Dios. No es seguro ni justo actuar contra la propia conciencia. En esto me afirmo. No puedo hacer otra cosa. Que Dios me ayude. Amén ${ }^{15}$.

En esta «hora gloriosa», nació el espíritu crítico del protestantismo. El sí evangélico a la gracia de Dios y justificación por la fe, se convirtió en el no protestante a la poderosa Iglesia de Roma.

\section{PARTE SEGUNDA: \\ La herencia de Wittenberg}

Wittenberg fue, en el camino de Lutero, un punto de llegada y de partida. Se había incorporado (en 1508) como profesor de Teología en su universidad, fundada en 1502 por Federico III, elector de Sajonia (1463-1525). Allí publicó sus Las 95 tesis (1517). Pero también Wittenberg es el punto de partida de «la herencia evangélica» de la Reforma con su rica y compleja diversidad y su posterior expansión mundial ${ }^{16}$.

Quien escribe esta reflexión recuerda, por haber participado en muchas celebraciones, cómo el protestantismo costarricense, en la década de los cincuenta y sesenta del siglo pasado, realizaba cada 31 de octubre el «Culto del Día de la Reforma». Se recordaba, así, el día en que Lutero clavó Las 95 tesis. En el acto público se cantaba el himno lema de la Reforma, «Castillo fuerte es nuestro Dios», escrito por Lutero en $1527^{17}$.

Ser hijos e hijas de la memoria mueve, con renovada conciencia histórica, a mantener viva la gesta profética de Lutero y a celebrar el redescubrimiento del evangelio de la gracia, de la trasformación personal y el don de la gloriosa libertad de los hijos e hijas de Dios (Rom. 8:14-15), asumiendo permanentemente la tarea de radicalizar la reforma eclesial, en compromiso con el mundo justo de Dios, con paz, solidaridad e integridad de la creación agredida.

14. Edwin P. Booth, Martín Lutero. Roble de Sajonia (Buenos Aires: La Aurora, 1955), 109.

15. Martin Lutero, Páginas escogidas..., 49.

16. Julio De Santa Ana, «Protestantismo», en Nuevo diccionario de Teología, dirigido por Juan José Tamayo (Madrid: Trotta, 2005), 508-517. Para una visión del protestantismo en América Latina, confróntese la obra de: José Míguez Bonino, Rostros del protestantismo latinoamericano (Buenos Aires: Nueva Creación, 1995).

17. Sobre el himno «lema de la Reforma», escrito por Martin Lutero, confróntese el siguiente sitio web: https://es.wikipedia.org/wiki/Castillo_fuerte_es_nuestro_Dios 
El «sí» a la gracia se expresa a partir de cinco presupuestos, los cuales constituyen, según José M. G. Gómez-Heras, profesor de Teología Protestante en Salamanca, «la quintaesencia teológica de la interpretación evangélico-protestante del cristianismo» ${ }^{18}$. Estos presupuestos teológicos van dirigidos contra cualquier intento de eliminar «la divinidad de solo Dios», «la soberanía de solo Cristo», «la gratuidad de la sola gracia», «la suficiencia de la Sola Scriptura», «la libertad de la sola fe» ${ }^{19}$.

El énfasis se condensa en formulaciones breves, donde la palabra clave es «sola $»^{20}$. La protesta reformada es el reverso de un sí no menos radical y exclusivo, para el que José M. G. Gómez-Heras ofrece la siguiente lectura:

- El solus Deus expresa la soberanía y suficiencia de Dios

- El solus Christus manifiesta la concreción histórica de Dios en Cristo y de la reconciliación del mundo con Dios.

- El sola Gratia expresa que la salvación del ser humano proviene solo de Dios y acontece como regalo de Dios.

- El sola Scriptura plantea la Biblia como la única norma de fe y quiere ser un testimonio de fidelidad a la Palabra de Dios.

- El sola Fides propone que la justificación se lleva a cabo no mediante aporte alguno del ser humano, sino mediante la confianza de quien cree en lo que Dios ha hecho por gracia $^{21}$.

A continuación, se observan algunas de sus implicaciones.

\section{«Solo Dios»: Teocentrismo radical}

El teocentrismo expresa la voluntad de permitir que Dios sea Dios, misterioso, santo e inmanipulable, siempre mayor. La Reforma representa la ruptura liberadora del paradigma de comprensión de Dios en la teología medieval: la imagen de Dios no es ya una idea abstracta elaborada por teólogos con categorías filosóficas. La Reforma hizo posible el retorno al Dios de la Biblia. Del misterio del «Dios-en-sí» (ontología) se pasa al «Dioscon-nosotros y nosotras», el Eterno Emmanuel. Dios como luz y salvación. La gracia es Dios mismo, acercándose al ser humano para salvarlo, estableciendo un encuentro e intercambio vital.

La gracia supone la ruptura de la inmutable pirámide ontológica, tal cual la definió la filosofía griega; según esta, el ser humano pertenece al mundo material-inferior (abajo), mientras que Dios pertenece al mundo espiritual-superior (arriba). Desde esta lógica

\footnotetext{
18. José M. G. Gómez-Heras, Teología protestante, (Madrid: La Católica, 1972), 14.

19. Ibíd.

20. Jean Baubérot y Jean-Paul Willaine, El protestantismo de A a Z (Barcelona: Gayata, 1996), 107-109.

21. José M. G. Gómez-Heras, Teología protestante..., 13-14.
} 
piramidal, el ser humano no puede subir adonde está Dios, ni Dios puede bajar donde está el ser humano ${ }^{22}$. La gracia es todo lo contrario: Dios ha tomado la iniciativa de acercarse; la frontera entre Dios y el ser humano está abierta, y todo eso acontece gratuitamente.

De esta forma, la reflexión sobre Dios y la gracia acaban accediendo a la cristología. El teocentrismo radical de la Reforma se transformó en mediación cristocéntrica. «El sí evangélico quiere ser un sí a Cristo y el no protestante una repulsa a toda mediación que compita con Cristo» ${ }^{23}$. Se rompe con la concepción de una Iglesia sacramental, como autoridad superior en la tierra, intercesora entre Dios y el ser humano, y mediadora del destino eterno del ser humano. Olvidando la mediación cristocéntrica, la Iglesia exigía, a cambio de la salvación, total obediencia y el cumplimiento riguroso exterior de ritos, mandamientos y obras de sacrificio.

\section{"Sola Gratia»: Gratuidad salvífica}

La dramática lucha existencial de Lutero cambiaría. Llegó a exclamar, en virtud de la gracia, que «las puertas del cielo se abrieron para mí» ${ }^{24}$.

La salvación esperada proviene de Dios como el don que recibimos mediante la sola fe, y no por méritos u obras. A Dios no le podemos comprar misericordia, porque Dios es feliz dando.

La gracia desintegra la religión del trueque comercial regida por la lógica de la igualdad del intercambio. De ahí el principio de dar a las otras personas lo que a cada una le corresponde. Según este intercambio, Dios tendría que actuar conforme a lo que el ser humano hace, da o compra.

Lutero conocía solo el principio de «justicia conmutativa», y no el que enseña la Biblia, de «justicia salvífica». De ahí la crisis, su temor permanente al rechazo: si Dios me tiene que dar conforme a lo que merezco por mis pecados, lo justo será una sentencia condenatoria.

La justicia salvífica de Dios es una salvación atípica fundamentada en el amor. La justicia de Dios se consuma como vida y justificación; no como ajusticiamiento del reo, sino como su justificación ${ }^{25}$. Por su gracia, Dios me otorga, no lo que merezco, sino lo que más necesito: amor, perdón, vida. Un amor que endereza lo que en estricta justicia solo se podría sancionar con una condena. Por gracia de Dios, la justicia no se consuma con el ajusticiamiento del prisionero, sino con su justificación, suscitando una vida agraciada ${ }^{26}$.

\footnotetext{
22. Juan Luis Ruiz de la Peña, Creación, gracia, salvación (Santander: Sal Terrae, 1993), 86.

23. José M. G. Gómez-Heras, Teología protestante..., 16.

24. Roland H. Bainton, Lutero..., 67.

25. Juan Luis Ruiz de la Peña, Creación, gracia, salvación..., 118.

26. Ibíd., 18.
} 
El corazón de la Reforma es la teología de la justificación por la fe mediante la gracia. El binomio inseparable: sola Gratia-sola Fide ${ }^{27}$.

Para la Reforma la fe es fiducia, plena confianza en $\operatorname{Dios}^{28}$. Así se establece una relación personal con Dios y se rescata la dimensión bíblica de la fe.

Es muy significativo el énfasis que en «la fe» ofrece la traducción de Juan Mateos (1917-2003), erudito exégeta católico, a propósito del texto de Rom. 1:17, tan decisivo para Lutero: «En el evangelio se revela la justicia que Dios concede única y exclusivamente por la fe» $\rangle^{29}$. El texto griego dice literalmente «de fe a fe» ${ }^{30}$, expresión inspirada en otra aramea con el significado de «empezando por (la fe) y acabando por (la fe)» ${ }^{31}$.

La Reforma, al insistir en este punto medular, transformó el sentido de la fe: la fe es una actitud personal, libre, mediante la cual se coloca plenamente la confianza en un Dios gratuito y se acogen sus promesas (fe-esperanza). La fe en un acto personal que compromete toda la vida. Dada la fragilidad humana, se pone toda la confianza en lo que Dios ha hecho en favor de las todas las personas.

\section{«Sola Escritura»: Fidelidad a la Palabra de Dios}

Durante 1500 años o más, la Biblia no fue el centro de la vida de la Iglesia. Circulaba restringida solo en latín. La única interpretación válida de sus textos era la que declaraba la Iglesia. La Reforma marcó el retorno a las fuentes bíblicas, la promoción de su lectura y difusión. Se redescubrió su autoridad por encima de la tradición, de los teólogos, concilios y el magisterio del romano pontífice.

En la Dieta de Worms en 1521, cuando Lutero fue presionado para retractarse de sus escritos, declarados por la ortodoxia romana como heréticos, en su palabra firme de no retractación, señaló que solo podría hacerlo si se le convencía, con el testimonio de las Sagradas Escrituras, de que estaba equivocado: «Yo estoy ceñido por los textos de la Biblia, mi conciencia es cautiva de la Palabra de Dios» ${ }^{32}$.

En Wartburgo (1521-1522), Lutero emprendió uno de sus mayores legados: la traducción de la Biblia a la lengua alemana. Tradujo primero el Nuevo Testamento (1522) y en 1534 se imprimió la Biblia completa. Mérito indiscutible de la Reforma fue su empeño por traducir la Biblia a las lenguas vernáculas y colocarla directamente en manos del pueblo. Así este pudo leer directamente la verdad del evangelio que le otorgaba vida, libertad y dignidad.

27. Elsa Tamez, «Justificación y justicia» ..., 508-514.

28. Justo González, Diccionario teológico (Barcelona: Clie, 2010), 127.

29. Juan Mateos y Luis Alonso Schökel, Nuevo Testamento (Madrid: Cristiandad, 1987), 785.

30. Elsa Tamez e Isela Trujillo, El Nuevo Testamento. Interlineal griego-español (Brasil: Sociedades Bíblicas, 2012), 569.

31. Juan Mateos y Luis Alonso Schökel, Nuevo Testamento..., 786.

32. Martin Lutero, Páginas escogidas..., 49. 
Es fascinante saber que los reformadores no comenzaron desarrollando una doctrina sobre la autoridad de la Biblia, que les obligara a tomar en serio su mensaje. [...] El Dios de la gracia les habló por medio de ésta, estableciendo de este modo su autoridad [...] Al responder, fueron obligados a afirmar el poder de la palabra presentada por la Biblia para ordenar todo el pensamiento cristiano y todos los aspectos de la vida en la Iglesia y el mundo ${ }^{33}$.

\section{Afirmaciones distintivas}

A partir de la quintaesencia teológica de la Reforma, se destacan tres notas importantes de la permanente herencia e identidad protestante: la libertad cristiana, el sacerdocio del creyente y el testimonio del Espíritu Santo.

\section{Afirmación de la libertad cristiana}

La gracia de Dios aceptada por fe hace al cristiano libre. La dialéctica don de la gracia-libertad cristiana es una manifestación de gracia. «El "sí" a la gracia es un acto de genuina libertad $»^{34}$.

La Iglesia, con su poderosa estructura institucional, se había convertido en un obstáculo para la vida del creyente. La vida cristiana no era libre. A cambio de su protección y mediación entre Dios y los seres humanos, la Iglesia exigía total obediencia. La respuesta era la sumisión y el miedo a la libertad. No existía la libre decisión, ni la responsabilidad personal de cada creyente.

Con la Reforma las cosas cambiaron. Cobró importancia la persona, la existencia agraciada, una nueva manera de ser justificado por la fe. Ahora la persona es protagonista. Libremente responde al don de Dios. La respuesta procede de cada persona. El creyente libre ante Dios -atraído por su gracia- es sujeto responsable en una relación personal directa y amorosa con Dios.

En noviembre de 1520, Lutero publicó su pequeño tratado sobre «La libertad cristiana». Allí escribió su clásico pensamiento: «El cristiano es el más libre señor de todas las cosas, y no está sujeto a nadie. El cristiano es sumiso servidor de todos y está sujeto a todos $»^{35}$.

La libertad cristiana, como espacio de gracia, es espacio de responsabilidad y diaconía por amor a las personas. Conlleva la grave tarea de ser, como lo dijo Lutero; «un Cristo para los demás $»^{36}$. Dietrich Bonhoeffer (1906-1945), teólogo y pastor luterano, mártir por su resistencia al nazismo, definió a Cristo como «el ser para los demás» ${ }^{37}$.

33. Richard Shaull, La Reforma y la teología de la liberación..., 46.

34. Juan Luis Ruiz de la Peña, Creación, gracia, salvación..., 94.

35. Edwin P. Booth, Martín Lutero. Roble de Sajonia..., 108.

36. Richard Shaull, La Reforma y la teología de la liberación..., 30.

37. Rosino Gibellini, La teología del siglo XX (Santander: Sal Terrae, 1998), 119. 
Como portador del mensaje de la gracia de Dios, toda persona cristiana se convierte en un sacerdote. Si cada persona cristiana es «un Cristo para el prójimo», puede libremente presentarse ante todas las otras como sacerdote, proclamar la gracia y la justificación, orar por las personas y enseñar el mensaje del mundo justo de Dios.

Este es el fundamento, la vocación más alta del cristiano. En consecuencia, la vida del creyente más humilde, que vive y trabaja en el mundo cotidiano secular, es tan importante ante Dios como la de cualquier sacerdote, la mística que anteriormente se atribuía a la vida ascética de los religiosos se traslada aquí a todos los cristianos. Para Lutero eso se aplica a todo creyente, incluyendo a los del peldaño más humilde de la escala social ${ }^{38}$.

El sacerdocio universal relativiza la diferencia entre clérigos y laicos, y la sacralización de las estructuras jerárquicas de poder en la Iglesia. Ninguna persona o grupo tiene el monopolio de ser el canal único de la gracia. La Iglesia es Pueblo de Dios, la comunidad de todas las personas creyentes discípulas de Jesús en un camino de seguimiento que busca hacer presente y creíble históricamente el amor y el mundo justo de Dios.

\section{Afirmación del testimonio interior del Espíritu Santo}

Sellados por el Espíritu prometido (Ef. 1:13), la persona creyente está llamada a vivir guiada por el Espíritu que vive en nosotros (Rom 8:4) como primicia. Ello conduce hacia la vida y la paz (Rom. 8:6). El Espíritu testifica a nuestro espíritu que somos hijos e hijas de Dios: «Mirad, no recibimos un espíritu que nos haga personas esclavas y nos regrese al temor, recibimos un Espíritu que nos hace hijos e hijas de Dios y que nos permite gritar: ¡Abba! ¡Padre-Madre!». Ese mismo le asegura a nuestro espíritu que somos hijos e hijas de Dios (Rom. 8:15), al servicio del amor (Gal. 5:13), hermanos y hermanas de Jesús y servidores de los más pequeños y vulnerables (Mat. 25).

\section{PARTE TERCERA:}

\section{La herencia de la Reforma en el hoy latinoamericano: Perspectivas éticas}

Cinco siglos nos separan ya de los acontecimientos fundantes de la Reforma del siglo XVI. Surge la pregunta por su pertinencia en el hoy cronológico latinoamericano ${ }^{39}$. En el mundo todo cambia y, por tanto, surgen nuevos paradigmas, luchas específicas

38. Richard Shaull, La Reforma y la teología de la liberación..., 33.

39. En diciembre de 1985, teólogos luteranos de los Estados Unidos y América Latina celebraron, en la ciudad de México, una consulta sobre la viabilidad de Lutero hoy. El tema fue «Justificación y justicia». Confróntese la Revista Vida y Pensamiento, No. 1 (1986).

El libro de Richard Shaull, La Reforma y la teología de la liberación (San José: DEI, 1993) propone un rico diálogo con aquella desde los procesos de liberación que deben conducirnos a una nueva y más radical reforma en la iglesia y la sociedad. En relación con esta misma temática también confróntese la obra de la biblista Elsa Tamez, Contra toda condena: La justificación por la fe desde los excluidos (San José: DEISEBILA, 1991). Además, confróntese los siguientes dos títulos de esta misma autora: «Justicia y justificación» en Conceptos fundamentales del cristianismo, Eds. Juan José Tamayo y Casiano Floristán (Madrid: 
y amenazas globales, que pesan gravemente sobre nuestro presente, comprometiendo el futuro de la vida humana y no humana en nuestra tierra.

La creciente pobreza ( 3 mil millones de personas en situación extrema en el mundo), la exclusión sociocultural, la pandemia de la violencia, el armamentismo, la corrupción, el narcotráfico, la intolerancia de los fundamentalismos, la agresiva destrucción de la tierra, el cinismo, el desencanto, así como la pérdida del valor y el sentido de la vida: estas son algunas dimensiones del amplio abanico de la complejidad de un mundo plural, insensible y cruel.

Ya no es posible responder los nuevos desafíos recurriendo a tiempos pasados. La buena nueva de la gracia de Dios tiene que vivirse en honradez con la realidad histórica, donde la desgracia destructora de la vida es cotidianamente omnipresente.

\section{Perspectivas}

Se hilvanan algunas perspectivas sobre la teología de la gracia en clave ética, desde la praxis de la fe, vivida como apuesta por una humanidad solidaria, en su rica diversidad, en lucha contra toda exclusión económica, cultural, de género, racial y sexual.

El sabio teólogo reformado Richard Shaull (1919-2002) ha señalado que «el corazón del protestantismo no es tanto una doctrina cuanto una nueva manera de ser en el mundo, especialmente, una nueva manera de lo que significa ser Iglesia, lo cual tiene implicaciones transformadoras para todas las instituciones de la sociedad $»^{40}$.

Se destacan tres ejes, una especie de «principios»: el principio de ecclesia reformanda, el principio de crítica profética y el principio gracia-misericordia.

\section{La Ecclesia semper reformanda}

Los calvinistas expresaron este principio clásico de renovación con la célebre frase ecclesia reformata, semper reformanda. Apunta al hecho de que cualquier iglesia nacida de la Reforma, es iglesia en la medida en que tenga la voluntad de reformarse, es decir, de vencer, con el paso del tiempo, la tentación de la autopreservación inherente a todas las instituciones humanas. También en la medida en que tenga la voluntad de responder creativamente a los desafíos del aquí y el ahora, y de ser una comunidad que no se aferra

\footnotetext{
Trotta, 1993), 664-675; «Justificación y justicia», en Nuevo Diccionario de Teología, dirigido por Juan José Tamayo, (Madrid: Trotta, 2005), 508-517.

Más recientemente, en el marco de la celebración de los 500 años de la protesta de Lutero en 1517, se ha publicado un importante aporte internacional, de personas teólogas de confesión luterana, el cual es el siguiente: Martin Hoffmann, Daniel C. Beros y Ruth Mooney, «Radicalizando la Reforma. Provocados por la Biblia y las crisis actuales: las 94 tesis», Aportes Teológicos, No 1 (2015). Resulta muy valiosa la propuesta que plantean estos autores acerca de las « 94 Tesis», las cuales son reflexionadas desde diferentes contextos geográficos, así como una gran variedad de tradiciones de la Reforma.

40. Richard Shaull, La Reforma y la teología de la liberación..., 6.
} 
a antiguos esquemas. «Es la manera de acompañar la acción transformadora del Dios vivo y que da vida en el mundo» ${ }^{41}$.

Este principio de renovación es de suma urgencia de cara a la liberación y revitalización de una iglesia profética. Urge continuar así, con la creatividad teológica y eclesiológica de los reformadores, al servicio del pueblo de Dios y la sociedad latinoamericana, y no para una élite religiosa jerarquizada, instruida, con puestos de autoridad en la Iglesia ${ }^{42}$.

Dietrich Bonhoeffer escribió proféticamente que «hemos aprendido a ver los grandes acontecimientos de la historia del mundo desde abajo, desde la perspectiva de los marginados, los sospechosos, los maltratados, los insultados, los pobres, los oprimidos, en suma, desde la perspectiva de los que sufren $»^{43}$.

Hoy, en nuestro contexto latinoamericano, necesitamos ver y escuchar «desde abajo», desde la insignificancia ${ }^{44}$. Un colectivo internacional de personas teólogas de confesión luterana y de otras confesiones ligadas al proyecto «Radicalizando la Reforma. Provocados por la Biblia y las crisis actuales», señalan que «Sólo si escuchamos el gemir de la creación abusada (Rom. 8:22), sólo si escuchamos activamente el clamor de quienes son victimizados en el lado inferior de nuestro orden mundial hipercapitalista, sólo entonces podremos convertir esta conmemoración de la Reforma en un jubileo liberador ${ }^{45}$.

\section{El espíritu de crítica profética antiidolátrica}

En la tradición protestante, se alude específicamente al «principio protestante», expresión acuñada por Paul Tillich (1886-1965) ${ }^{46}$. Refiere a la resistencia a conferir autoridad final y absoluta a cualquier ser o institución humana; al rechazo a todo absoluto, en la iglesia y en el mundo, que no sea Dios.

El principio protestante se concreta en el espíritu de crítica y autocrítica, de desacralización de todas las manifestaciones de la vida y de la sociedad ${ }^{47}$. Es el rechazo de toda construcción humana, institución, estructura económica, sistema político, ciencia, filosofía, ideología, raza, cultura o religión que reclame para sí valores, poderes o acatamiento absoluto.

Los profetas bíblicos lo vivieron (y sufrieron) como una lucha antiidolátrica. El desafío para la fe hoy no proviene tanto del ateísmo, o la increencia, cuanto de la idolatría ${ }^{48}$.

El «principio protestante» se arraiga en el teocentrismo (solo Deus) de los reformadores. Solo a Dios pertenece libérrimamente el ser Dios, de tal manera que, fuera de Él,

\footnotetext{
41. Ibíd., 67.

42. Ibíd., 51 y 62 .

43. Dietrich Bonhoeffer, Escritos esenciales (Santander: Sal Terrae, 2001), 150.

44. Elsa Tamez, «Justificación y justicia» ..., 514s.

45. Martin Hoffmann, Daniel C. Beros y Ruth Mooney, eds., Radicalizando la Reforma. Otra teología para otro mundo (San José: SEBILA, 2016), 15-40.

46. Justo González, Diccionario teológico..., 238.

47. Richard Shaull, La Reforma y la teología de la liberación..., 67.

48. Victorio Araya Guillén, El Dios de los pobres (San José: DEI, 1983), 149-154.
} 
cualquier pretensión de absolutizar lo humano es idolátrica y contraria a la liberación humana integral.

Dicho de forma abreviada, el principio protestante establece que «Dios es el único absoluto, todo lo demás es relativo». Traducido eclesialmente: «El Reino de Dios es el único absoluto, la Iglesia es relativa». Traducido socialmente: «El don de la vida, es el único absoluto, todo lo demás debe estar al servicio de su plenitud, sin exclusión».

En un mundo habitado por falsos ídolos y fetiches de opresión y muerte ${ }^{49}$ : el dinero, las dictaduras del poder, los ejércitos, «la religión económica» de mercado ${ }^{50} \mathrm{y}$ las producciones y consumo sin límites, cobra importancia decisiva hoy la práctica de un espíritu crítico que se acompaña de acciones proféticas de protesta, resistencia y transformación, en la defensa activa de la vida y de la integridad de la creación.

El humanismo secular insolidario se ha transformado en un antropocentrismo prometeico, que conduce al nacimiento de un ser humano autoexaltado, hasta su plena divinización. Hoy enfrentamos sus desastrosas consecuencias. La historia nos muestra trágicamente que, cuando el ser humano tiene la arrogancia de convertirse en un dios, aflora el lado oscuro de su demencia y cinismo, que lo convierte en «el satanás de la tierra», para destruir la vida humana personal, social y de la naturaleza. La rebelión contra Dios en nombre de la construcción del paraíso terrenal ha creado los peores infiernos en la tierra. Sus víctimas ven constantemente pintada ante sus ojos la realidad de la condenación, en el aquí y ahora terrenal ${ }^{51}$.

Hoy se enfrenta la posibilidad real, como lo ha señalado Leonardo Boff, de que el ser humano, autodenominado homo sapiens sapiens, convertido en homo [deus] demens demens, ya homicida y etnocida, se convierta en ecocida, destructor de nuestra casa común y única: la madre tierra (el agua, el aire, el clima, los animales, las plantas) ${ }^{52}$.

\section{La primacía de la gracia}

El aporte liberador de la Reforma consiste en recordar que la gracia remite «al concepto central de la fe cristiana» ${ }^{53}$, que Dios es solo gracia y toda gracia. Que la salvación -en una cultura pragmática y meritocrática- es favor inmerecido y gratuito, y no esfuerzo humano; Paul Tillich (1986-1965) lo ha formulado bellamente: la respuesta humana a la iniciativa de la gracia es la «aceptación», simplemente «aceptar que hemos sido aceptados» ${ }^{54}$.

En la libre aceptación de un Dios gratuito, que nos ama y nos acepta desde antes de que hiciéramos algo para merecerlo, se encuentra la estructura vertebral de la teología de

49. No pierde vigencia la obra: El Aporte Colectivo, La Lucha de los dioses. Los ídolos de la opresión y la búsqueda del Dios liberador (San José: DEI, 1980).

50. Juan José Tamayo, ed., Nuevo diccionario de teología (Madrid: Trotta, 2005), 901.

51. Victorio Araya Guillén, La luz de una candela (San José: UBILA, 2014), 104-105.

52. Leonardo Boff, El despertar del águila (Madrid: Trotta, 2000), 17.

53. Casiano Floristán y Juan José Tamayo, Conceptos fundamentales del cristianismo (Madrid: Trotta, 1993), 541

54. Paul Tillich, Se conmueven los cimientos de la tierra (Barcelona: Nopal, 1968), 256. 
la Reforma. La historia de la relación creación-ser humano-Dios es una historia de gracia que nace en el corazón de Dios quien, desbordante de gratuidad, «nos amó primero» (1 Jn. 4:10).

Pero la historia no termina allí. A través del acto creador, nos convoca a su proyecto de vida y de salvación. La gracia es don y tarea, que supera la individualización de la gracia. Es exigencia de vivir responsablemente, de forma compasiva y solidaria, participando activamente en el sueño de una plenitud posible para todas las personas, practicando la justicia, la paz y la liberación del tramado de la vida plena en la casa-tierra.

\section{La gracia como bendición vital}

Se esbozó una clave de lectura y profundización de la buena noticia de la gracia. La destrucción agresiva y sistemática del don de la vida precisa una reorientación hacia una nueva cultura de la vida ${ }^{55}$ fundamentada en una opción preferencial por la vida, la bendición vital, el mayor don que se nos ha conferido ${ }^{56}$.

La fuente de la bendición vital es la primigenia correlación Dios-gracia-vida. Dios como el origen de la vida que anima la creación, y que la renueva con su aliento-energía amorosa paternal-maternal ${ }^{57}$.

Al mismo tiempo, la vida es el don más amenazado. El empobrecimiento creciente de la mayor parte de la humanidad, la pandemia de la violencia omnipresente y la agresiva destrucción de la naturaleza son ejemplos de las graves amenazas a la vida.

La gracia nos libera y por el Espíritu nos potencia para comprometernos responsablemente con el proyecto del don de la vida y experimentar históricamente una nueva dimensión del Espíritu: la vivencia de la espiritualidad profética de resistencia y transformación.

La espiritualidad nos fortalece en medio de la gravedad de las crisis globales y nos ayuda para resistir y abrir, esperanzadoramente, espacio a soluciones constructivas que enriquecen y mantienen humana la vida. La espiritualidad es asumir la bendición vital como don y tarea ${ }^{58}$, esto es, como compromiso de:

- Amar, celebrar y cuidar la vida y su rica biodiversidad natural y cultural.

- Potenciarla en su plenitud; la vida sí, pero toda la vida.

- Promoverla y defenderla compasiva y solidariamente, como bendición para todos, ante las múltiples amenazas, locales y globales.

- Trascenderla, esto es, vivir la espiritualidad como apertura desde la materialidad de vida, hacia la trascendencia (ultimidad de la vida).

55. Martin Hoffmann, Daniel C. Beros y Ruth Mooney, eds., Radicalizando la Reforma..., 16.

56. Victorio Araya Guillén, Caminata en la luz (San José: Arboleda, 2015), 161-165.

57. Geiko Müller Fahrenholz, El Espíritu de Dios. Transformar el mundo en crisis (Santander: Sal Terrae, 1996), 52-53, 118

58. Victorio Araya Guillén, Caminata en la luz..., 160-161. 


\section{Conclusión}

La lucha de Lutero por la liberación personal y eclesial lleva la huella de su momento histórico y social. El contexto social latinoamericano y eclesial es muy distinto. Existen nuevas preguntas y vivimos nuevas luchas existenciales y amenazas globales que gravitan sobre nuestro presente comprometiendo de manera vital nuestro futuro, no solo en América Latina.

El descubrimiento liberador de la gracia será siempre un kairós, esto es, un tiempo oportuno y desafiante. La historia de la relación entre el ser humano y el Dios de la gracia continúa como buena noticia, no obstante, la trágica presencia del pecado estructural en el mundo, con sus poderosos mecanismos y agentes al servicio de la destrucción de la vida. Pero, como afirma Pablo, «mas cuando el pecado abundó, sobreabundó la gracia» (Rom. 5:20).

«Vida en plenitud» es la palabra de gracia, el sí que Dios pronuncia sobre la creación, su don mayor. Para el creyente justificado por la fe mediante la gracia, creer es vivir comprometidamente una praxis de amor, «compasiva y solidaria, en relaciones justas con los demás y con todas las criaturas $\rangle^{59}$. Dios invita a participar y acompañarlo en su pasión amorosa y sufriente por la vida, en defensa de los pequeños y vulnerables. El Dios de la gracia es el Dios solidario con las personas pobres y vulnerables.

La fidelidad al espíritu profético de la Reforma del siglo XVI pasa por los caminos de la ortopraxis, concretada en una opción preferencial por la vida plena, hacia una cultura de la vida, con justicia inclusiva (económica, de género, climática, etc.), con paz, tolerancia, escucha, alegría, esperanza y la firme solidaridad hacia la creación crucificada y destruida con violencia. De esta manera, el sueño radicalizado de los reformadores, continuará vigente, y la teología de la gracia no será letra muerta, sino poder liberador, crítico profético, para la resistencia y la transformación. Gracia (amor gratuito y generoso), mundo justo de Dios (contra toda condena) y vida en plenitud para toda la humanidad, (nueva humanidad solidaria, nueva creación) marcan el camino que se hace al andar, construyendo el duro presente, forzando el nuevo mañana, que ya no permite esperar.

Se concluye con las palabras de un lúcido profeta contemporáneo, testigo de la gracia, el obispo anglicano de Sudáfrica, Desmond Tutu, premio Nobel de la Paz (1984):

«Yo tengo un sueño», dice Dios. Por favor ayúdenme a hacerlo realidad. Es un sueño de un mundo donde la fealdad, la pobreza y la miseria, la guerra y la hostilidad, la ambición y la competencia deshonesta, la alienación y la discordia sean transformadas en todo lo contrario: un mundo en el que haya belleza, alegría y paz, donde haya justicia, bondad, compasión, amor, solidaridad y armonía. Yo sueño con que el león vuelva a convivir con el cordero, con que la espada se convierta en arado, y las lanzas en tijeras para podar; con que mis hijos e hijas sepan que son miembros de una sola familia, la familia humana, la familia de Dios, mi familia ${ }^{60}$.

59. Martin Hoffmann, Daniel C. Beros y Ruth Mooney, eds., Radicalizando la Reforma..., 19.

60. Desmond Tutu, Dios tiene un sueño (Bogotá: Norma, 2004), 18-19. 


\section{ABSTRACT}

\section{Wittenberg protest (1517). Theological perspectives from the latinamerican context (2017)}

It starts from Martin Luther protest against indulgencies in October 1517. His discovery of the grace in the context of his dramatical spiritual struggle is established. The bases of the evangelicprotestant interpretation are highlighted, expressed in just the word, in three corollaries: liberty, universal priesthood, and the holy spirit testimony. It concludes with a reflection on the contribution of the Latin American Reform. Three core ideas are emphasized: the semper church reformed, the principle of anti-idolatrous criticism, and the primacy of the grace as a vital blessing, the mayor gift from God. The spirit of life as an impulse for a prophetic praxis: the preferential option pro-life to live spirituality.

Key words: reform, grace, justification of faith, protestant principle, life, spirituality.

\section{RÉSUMÉ}

\section{La protestation de Wittenberg (1517). Perspectives théologiques du contexte latinoaméricain}

Cet article part de la protestation de Martin Luther en octobre 1517 contre les indulgences et situe la découverte de la grâce dans un contexte de lutte spirituelle dramatique. Les principes essentiels de l'interprétation protestante-évangélique sont soulignés et exprimés dans un seul mot et les trois corollaires : liberté, sacerdoce universel et Dieu a le visage du Crucifié et regarde radicalement en bas (Magnificat). Cependant, le témoin du Sain Esprit. L'article conclue avec une réflexion sur l'apport de la Réforme en Amérique Latine axée sur : l'église semper reformanda, le principe de la critique contre l'idolâtrie et la primauté de la grâce comme bénédiction vitale, le don le plus grand de Dieu. L'Esprit Saint, souffle de vie, comme l'élan pour une praxis prophétique : choisir la vie comme manière d vivre l'spiritualité.

Mots-clés: Reforme, grâce, justification par la foi, principe protestant, vie et spiritualité.

\section{Bibliografía}

Aporte Colectivo. La lucha de los dioses. Los ídolos de la opresión y la búsqueda del Dios liberador. San José: DEI, 1980.

Araya Guillén, Victorio. Caminata en la luz. San José: Arboleda, 2015.

. La luz de una candela. San José: UBILA, 2014.

. El Dios de los pobres. San José: DEI, 1983.

Bainton, Roland H. Lutero. Buenos Aires: Sudamericana, 1955.

Baubérot, Jean y Jean-Paul Willaine. El protestantismo de A a Z. Barcelona: Gayata, 1996.

Boff, Leonardo. El despertar del Águila. Madrid: Trotta, 2000.

Bonhoeffer, Dietrich. Escritos esenciales. Santander: Sal Terrae, 2001.

Booth, Edwin P. Martín Lutero. Roble de Sajonia. Buenos Aires: La Aurora, 1955.

Cohn-Sherbock, Lavinia. Quién es quién en el cristianismo. Madrid: Acento, 2002.

Julio De Santa Ana. «Protestantismo». En Nuevo diccionario de Teología, dirigido por Juan José Tamayo. Madrid: Trotta, 2005.

Floristán, Casiano y Juan José Tamayo. Conceptos fundamentales del cristianismo. Madrid: Trotta, 1993. 
Gibellini, Rosino. La teología del siglo XX. Santander: Sal Terrae, 1998.

Gómez-Heras, José M. G. Teología protestante. Madrid: La Católica, 1972.

González, Justo. Diccionario teológico. Barcelona: Clie, 2010.

Hoffmann, Martín. La locura de la Cruz. La teología de Martín Lutero. San José: DEI, 2014.

Hoffmann, Martín, David C. Beros y Ruth Mooney, eds. Radicalizando la Reforma. Otra teología para otro mundo. San José: SEBILA, 2016.

Lutero, Martín. Páginas escogidas. Buenos Aires: La Aurora, 1961.

Mateos, Juan y Luis Alonso Schökel. Nuevo Testamento. Madrid: Cristiandad, 1987.

Míguez Bonino, José. Rostros del protestantismo latinoamericano. Buenos Aires: Nueva Creación, 1995.

Müller-Fahrenholz, Geiko. El Espíritu de Dios. Transformar el mundo en crisis. Santander: Sal Terrae, 1996.

Prévost, Jean-Pierre. Diccionario de los salmos. Estella: Verbo Divino, 1990.

Rossano, Pietro. Nuevo diccionario de Teología Bíblica. Madrid: Paulinas, 1990.

Ruiz de la Peña, Juan Luis. Creación, gracia, salvación. Santander: Sal Terrae, 1993.

Shaull, Richard. La Reforma y la teología de la liberación. San José: DEI, 1993.

Stolee, Ingeborg. Vida de Lutero. Minneapolis: Augsburg, 1955.

Tamayo, Juan José, ed. Nuevo diccionario de Teología. Madrid: Trotta, 2005.

Tamez, Elsa. «Justificación y Justicia». En Nuevo diccionario de Teología, dirigido por Juan José Tamayo, 508517. Madrid: Trotta, 2005.

Tamez, Elsa e Isela Trujillo. El Nuevo Testamento. Interlineal griego-español. Brasil: Sociedades Bíblicas, 2012.

Tillich, Paul. Se conmueven los cimientos de la tierra. Barcelona: Nopal, 1968.

Tutu, Desmond. Dios tiene un sueño. Bogotá: Norma, 2004. 